\title{
Introduction to special issue: unpacking the Chinese dream of homeownership
}

\author{
Youqin Huang ${ }^{1} \cdot$ Shenjing $\mathrm{He}^{2} \cdot \mathrm{Li} \mathrm{Gan}^{3,4}$
}

Accepted: 13 February 2021 / Published online: 20 February 2021

(C) This is a U.S. government work and not under copyright protection in the U.S.; foreign copyright protection may apply 2021

China has achieved the "Chines Dream" of homeownership and transitioned to an ultraownership society within a very short span of less than three decades. In much of the second half of twentieth century, China was a mass public rental society with private homeownership accounting for less than $30 \%$ (Huang 2004). Housing was considered a social welfare benefits provided with heavy subsidies by the socialist government and public employers, and private housing and homeownership were discouraged. However, since the 1990s, China has launched housing reforms to privatize and marketize its housing system, as part of the market transition. In addition to privatizing existing public housing and ending the provision of subsidized rental housing, private housing development and homeownership have been fervently encouraged (State Council 1998). As a result, homeownership has skyrocketed, reaching $85 \%$ in 2010 nationwide (70\% in cities) and more than $90 \%$ in 2017 (87\% in urban and 96\% in rural China) (Yi and Huang 2014; Clark et al. 2019). China now is one of the countries with the highest rate of homeownership in the world. Multiple home ownership is also rising rapidly, reaching $20 \%$ and higher than many developed nations (Huang and Yi 2011; Huang et al. 2020). This rapid and pervasive change is particularly impressive and in sharp contrast to the recent decline in homeownership and the emergence of "generation rent" in the West (Forrest et al. 2012; Clark 2019; Richard 2018).

While this profound transformation into a homeownership society seems to follow the Western path in earlier decades, the Chinese case stands out with not only its speed and

Youqin Huang

yhuang@albany.edu

Shenjing He

sjhe@hku.hk

Li Gan

gan@chfs.cn

1 Department of Geography and Planning, University at Albany, State University of New York, Albany, USA

2 Department of Urban Planning and Design, University of Hong Kong, Pok Fu Lam, Hong Kong

3 Department of Economics, Texas A\&M University, College Station, USA

4 Research Institute of Economics and Management, China Household Finance Survey (CHFS) and Research Center, Southwestern University of Finance and Economics (SWUFE), Chengdu, China 
scale, but also its unique context of the socialist history and the dominant role of the state. How is the Chinese case resonate with the Western experience? How did China achieve such a high rate of homeownership quickly? What are the unique roles of the state and family working with the market in China compared to the West? What are the social, political and economic implications? Is this high level of homeownership in China sustainable and what is the future trajectory? Are Chinese young adults facing similar challenges in their transition to homeownership as those in the West? As we witness the historic transformation taken place in China, many questions beg for answers.

There is a growing body of literature on homeownership in China that have helped us to understand this shift to homeownership in China. For example, many studies find that tenure decision in China is shaped by not only socioeconomic and market factors as is the case in market economies, but also institutional forces unique to China such as housing subsidies, the nature of employers (work units), and individual political status within work units (e.g. Huang and Clark 2002; Huang 2004; Li 2000; Li and Li 2006; Li and Yi 2007a, b). There is a consensus that while the housing market is becoming increasingly more important over time, institutional forces continue to be significant despite ongoing reforms. It is also clear that housing and homeownership have contributed to rising social and wealth inequality in China, especially between the propertied and property-less (e.g. Huang and Li 2014; Huang and Jiang 2009; Sato 2006; Wang and Murie 2000; Wang et al. 2020). In particular, with institutional discriminations embedded in the Household Registration (hukou) System, migrants in cities have been largely excluded from not only subsidized housing but also homeownership and wealth accumulation, which further reinforces the gaps between migrants and local urban residents (e.g. Fang and Zhang 2016; Huang and Yi 2015; He et al. 2017; Jia et al. 2018; Wu and Zhang 2018). The recent Special Issue (2021) titled "Homeownership and Housing Divide in China" in Cities: The International Journal of Urban Policy and Planning, also guest edited by us, provides the latest assessment on the impact of homeownership on not only multi-dimensional inequality but also subjective wellbeing. However, compared to the large body of literature on homeownership in the West, much is still unknown on this historic transformation in China.

This special issue aims to better understand China's unprecedented achievement of a homeownership society, and its impact on Chinese people and society. It aims to examine how Chinese households especially young adults access homeownership, and how homeownership affects them socially and economically. This special issue is of theoretical and empirical significance for at least three reasons. First, China's socialist history and recent transition towards a market economy create a unique context to study homeownership especially in the post-2008 and neoliberal era. In addition to better understanding housing in China, research on China potentially can shed important lights on housing problems in the West such as rising housing inequality, the lack of affordable housing and difficulty in achieving homeownership especially among young adults and (im)migrants, and thus make significant theoretical contributions to the literature on housing, homeownership, social mobility and inequality. In particular, departing from a recent history of massive public housing, the rapid privatization and high rate of homeownership in China are highly relevant to other post-socialist countries that share a similar trajectory of shifting housing tenure structure. Thus understanding China also helps to better understand the transition to a homeownership society in other post-socialist countries.

Secondly, this issue pays special attention to young adults' homeownership in China, which resonates with the growing housing challenges among the young in the West. Since the 2008 financial and housing crisis, it has become increasingly more difficulty for young adults to afford decent housing, live independently, and achieve homeownership. Many 
young adults from North America to Asia, from Europe to Latin America, have to move back to live with parents and fail to launch their own housing career. This housing challenge significantly affects young adults' socioeconomic wellbeing and mobility and exacerbates socioeconomic and intergenerational inequality. At the macro level, young adults' housing difficulties can threaten economic productivity, social development, and political stability, as indicated by the discontent and socioeconomic instability in Hong Kong in recent years (Forrest and Xian 2018). Thus there is an urgent need to better understand young adult's housing challenges. There has been an increasing research interests on young adults' housing in recent years in the West, and the concept of "generation rent" implies the difficulties young adults face in their transition to homeownership (e.g. Clapham et al. 2014; Clark 2019; Forrest and Yip 2012; Mackie 2012; McKee 2012; Ronald 2018). In China, young adults mostly grow up in the post-reform era, who no longer have access to housing subsidies (unlike their parents) but have to face skyrocketing housing prices especially in large cities. Thus young adults in China share similar challenges in housing access and affordability as those in other countries. In particular, young migrants in Chinese cities face additional institutionalized housing discrimination, and it is extremely difficult for them to access decent and affordable housing. Yet, young adults in China seem to fair much better, and have an unprecedently high rate of homeownership (70\%), probably a result of both inter-generational transfer and the institutional dividend their parents received. Thus young adults in China deserve scrutiny in their pursuit of housing dreams, which will contribute to our better understanding of the global housing challenges facing young adults, and shed light on the search for solutions for young adults' housing challenges.

Thirdly, this issue provides an up-to-date study of homeownership in China at the national level, using a unique large scale national survey data. Despite rapid increase in homeownership in China, we still know relatively little about this process and its impact. The relatively recentness of this change (mainly in the last two decades) and the lack of good national level micro-data with detailed housing information (even the dated 2010 census micro level is not available to the public) are main reasons. Most existing studies on homeownership in China use small-scale surveys and conduct case studies of specific cities (e.g. Huang 2004; Huang and Clark 2002; Huang and Yi 2010, 2011; Li 2000; Li and Li 2006; Li and Yi 2007a, b; Zhang 2010; Fang and Zhang 2016; Cui et al. 2016). Papers in this special issue all utilize the large-scale national survey data conducted by China Household Finance Survey and Research Center at Southwestern University of Finance and Economics in 2011, 2013, 2015, and 2017. This unique survey collects rich housing, income, wealth and assets information in addition to conventional socioeconomic indicators (see http://chfs.swufe.edu.cn for more details). These surveys provide an unprecedented, valuable opportunity for scholars to study housing, homeownership and socioeconomic wellbeing.

This special issue is organized around three sub-themes, namely (1) Access to Homeownership, (2) Young Adults' Housing Dream, and (3) the Effect of Homeownership. Papers are summarized below.

\section{Theme 1 access to homeownership}

Three papers in this section examine how Chinese households achieve homeownership and contribute to our understanding of the extremely high rate of homeownership in China. In addition to providing a holistic picture of homeownership access and studying the effect of 
the market, institutional constraints, and family support, these papers also examine the role of housing market sentiments and marriage market and sex ratio in achieving homeownership. Differences and inequalities in homeownership between cohorts, regions, and urban and rural households are scrutinized as well.

The paper by Cui, Deng and Lu adopts the 'state-market-family triad' in Esping-Andersen's welfare state regime to examine three main pathways to homeownership in Chinese cities: market-acquired, public-subsidized, and family-supported, and how it differs between different birth cohorts. Using 2013 CHFS, their empirical analysis demonstrates that the responsibility for housing provision has increasingly shifted from the state to the market, while families have become a vital social institution assisting young cohorts to achieve homeownership. There are clear generational differences, with older generations more likely to access homeownership via public-subsidized path, while younger generations are more likely to access via marketacquired and family-support paths as a result of the housing reform. Findings also show that higher educational attainment has enhanced people's independence from both the state and the family in terms of acquiring a home, while institutional factors, particularly hukou status, largely determine people's access to public-subsidized housing. Migrants in Chinese cities suffer double disadvantages as they usually cannot acquire homeownership through either public-subsidized or family support path. The results also show significant gender differences with men more likely to turn to family for housing support, reflecting the patriarchal traditions in property inheritance in China.

Paper by Dong, Hui and Yi tries to explain the high rate of homeownership in China from a rather different perspective- - housing market sentiment, a factor often ignored in housing research. It explores how housing market sentiment influences households' actual housingpurchasing decision and potential house-purchasing intention. Market sentiment is measured by a set of indicators related to housing market, land market, and capital market using Principal Component Analysis (PCA). After controlling household socioeconomic status and regional economic factors, results show that housing price and housing market sentiment play rather different roles in housing decisions. While higher housing price discourages actual house purchase and home-purchase intention, higher market sentiment encourages the decision of home purchase, especially the purchase of a second home, and among the younger generations. This study demonstrates the importance of market collective attitudes in housing decision and homeownership, and helps to explain the high rate of homeownership despite the prohibitively high housing prices in China. These findings have important implications to facilitate better-informed decision-making among homebuyers, property developers and policy makers.

Yang et al. focus on multiple home ownership and try to explain the high rate of multiple home ownership from the perspective of marriage market. With one-child policy and strong son preference, sex ratio in many parts of China is abnormally high with more men than women. To increase their sons' marriage prospect, parents may purchase additional homes for their sons. Their analysis shows that households with sons 25 +old are more likely to acquire additional homes, and the effect is stronger in regions with higher sex ratios, especially in rural areas. This finding is consistent with Huang et al. (2020) and Chai and Feng (2020), both of which argue that the patrilocal marriage tradition encourages parents with sons to buy multiple homes. 


\section{Theme II young adults' housing dream}

The second set of papers focuses on young adults in China and study how state, market, and family together shape young adults' housing consumption and homeownership. Clark, Huang and Yi provide an overall assessment of access to homeownership and its spatial and social variations, focusing on young adults (those born in 1970s, 1980s, and 1990s). Their empirical findings support China's transition to a homeownership society with widespread access to homeownership even among the millennials. Between 60 and $80 \%$ of young adults aged $28-47$ and $35 \%$ of those aged 18-27 own homes, which is much higher than their counterparts in the US and Europe. However, this transition to homeownership is a complex process shaped by institutional constraints, market forces, and family support and asset transfers, echoing three main pathways identified by Cui et al. in this issue. In addition to institutional factors such as hukou status in limiting migrants' access to homeownership, this paper stresses the importance of family support and asset transfer especially in millennials' homeownership. Behind the successful creation of a homeownership society, there are concerns of housing divide especially between migrants and local residents, as the former suffer not only the lack of affordability and parental transfers, but also institutional constraints, which is both similar to and different from that in the West.

Niu and Zhao focus on young adults aged 18-40, and study not only their homeownership, but also other dimensions of housing consumption, including living space, overcrowding, and housing wealth. With a similar framework to Clark, Huang and $\mathrm{Yi}$, they test the impact of institutional, market, and family related factors. Instead of actual family wealth transfer in the form of down payment and loans, Niu and Zhao use parents' socioeconomic status such as their education, hukou, and cadre status to indicate their ability to help children in housing. Findings are as expected with all three types of forces shaping housing consumption among young adults, which has important implication for social stratification. In particular, they stress the role of institutional forces and family background in both homeownership and housing wealth, which has long-lasting implications for social stratification.

Zhang and Bian focus on the role of family and provide an in-depth study of the inter-generational transfer to "the millennials" in China. Using two waves of CHFS, they examine the strength and timing of intergenerational transfer of housing-related wealth, and they identify three dominant types of housing-related wealth transfer with increasing strengths overtime: no substantial help from parents, partial help from parents to cover down payment for housing mortgage, and full help from parents in the form of homeownership transfer. They find that parental transfer in China follows the exchange model (instead of the altruism model and insurance model), and Chinese parents are impurely altruistic, son-preference oriented, and risk-avoiding in their decisions of transferring wealth to married children. Consequently, wealth transfers tend to benefit the less accomplished sons who have better parent-child relationships, fewer siblings, lower-risk marriages, and stronger commitment to repaying aging parents. It is clear intergenerational transfer in China is governed by a complex logic of emotional altruism, relational ethnics, and rational calculations. To some degree, this also reflects the rapid social transformation in aspects other than housing in China, such as population aging, higher divorce rate, and the weakening of the traditional family. 


\section{Theme III: the effect of homeownership}

The third set of papers examines the socioeconomic impact of homeownership, including happiness and investment. Chen et al. focus on multiple home ownership and find that multiple home ownership determines household investment portfolio. Their results show that multiple home ownership significantly crowds out the proportion of risky financial assets held by urban Chinese households. This reflects the substitution effect and people's awareness of risks associated with real estate. This crowding out effect is particularly significant and generally stronger for wealthy households and for regions with a medium development level of financial markets. It is clear that Chinese households consider multiple homeownership part of their investment strategy, probably a result of the lack of investment options and skyrocketing housing prices in China.

The second paper by Fong et al. focuses the impact of homeownership on happiness, comparing major social groups such as local urban residents, rural migrants and urban migrants. They find homeownership brings happiness to both rural migrants and local residents despite financial burdens, but interestingly it does not affect urban migrants. They also find that rural migrants who own homes in cities are significantly happier than those who own homes in villages, regardless they live in the owned homes or not. This suggests that the exchange value of owned homes may be more important than used value in China, which is consistent with homeownership as an investment strategy by Chen et al. in this issue and others.

Taken together, these eight papers present an in-depth and up-to-date examinations of the dynamics and the effect of homeownership in China. They help us better understand why China has achieved such a high rate of homeownership, especially among the young adults, and how homeownership is affecting Chinese socially and economically. While many questions remain and further research is warranted, this special issue has shed some important light on homeownership in China and made significant contribution to the general literature on housing.

\section{References}

Chai, K., \& Feng, C. (2020). Sons, daughters, and differentiated tenure choice of multiple homes: Evidence from urban China. Housing Studies, 1-27. https://doi.org/10.1080/02673037.2019.1709807.

Clapham, D., Mackie, P., Orford, S., Thomas, I., \& Buckley, K. (2014). The housing pathways of young people in the UK. Environment and Planning A, 46(8), 20162031.

Clark, W. A. (2019). Millennials in the housing market: The transition to ownership in challenging contexts. Housing, Theory and Society, 36(2), 206-227.

Cui, C., Geertman, S., \& Hooimeijer, P. (2016). Access to homeownership in urban China: A comparison between skilled migrants and skilled locals in Nanjing. Cities, 50, 188-196.

Fang, Y., \& Zhang, Z. (2016). Migrant household homeownership outcomes in large Chinese cities-the sustained impact of hukou. Eurasian Geography and Economics, 57(2), 203-227.

Forrest, R., \& Xian, S. (2018). Accommodating discontent: Youth, conflict and the housing question in Hong Kong. Housing Studies, 33(1), 1-17.

Forrest, R., \& Yip, N. M. (Eds.). (2012). Young people and housing: Transitions, trajectories and generational fractures. London: Routledge.

He, S., Liu, L., Yang, G., \& Wang, F. (2017). Housing differentiation and housing poverty in Chinese lowincome urban neighborhoods under the confluence of state-market forces. Urban Geography, 38(5), $729-751$.

Huang, Y. (2004). The road to homeownership: A longitudinal analysis of tenure transition in urban China (1949-1994). International Journal of Urban and Regional Research, 28(4), 774-795. 
Huang, Y., \& Clark, W. A. (2002). Housing tenure choice in transitional urban China: A multilevel analysis. Urban Studies, 39, 7-32.

Huang, Y., \& Jiang, L. (2009). Housing inequality in transitional Beijing. International Journal of Urban and Regional Research, 33, 936-956.

Huang, Y., \& Li, S. (Eds.). (2014). Housing inequality in Chinese cities. London: Routledge.

Huang, Y., \& Yi, C. (2010). Consumption and tenure choice of multiple homes in transitional urban China. International Journal of Housing Policy, 10(2), 105-131.

Huang, Y., \& Yi, C. (2011). Second home ownership in transitional urban China. Housing Studies, 26, 423-447.

Huang, Y., \& Yi, C. (2015). Invisible migrant enclaves in Chinese cities: Underground living in Beijing. China. Urban Studies, 52(15), 2948-2973.

Huang, Y., Yi, D., \& Clark, W. A. V. (2020). Multiple home ownership in Chinese cities: An institutional and cultural perspective. Cities, 97, 102518.

Jia, S., Wang, Y., \& Fan, G. Z. (2018). Home-purchase limits and housing prices: Evidence from China. The Journal of Real Estate Finance and Economics, 56(3), 386-409.

Li, S.-M. (2000). The housing market and tenure decisions in Chinese cities: A multivariate analysis of the case of Guangzhou. Housing Studies, 15, 213-236.

Li, S.-M., \& Li, L. (2006). Life course and housing tenure change in urban China: A study of Guangzhou. Housing Studies, 21, 653-670.

Li, S.-M., \& Yi, Z. (2007a). Financing home purchase in China, with special reference to Guangzhou. Housing Studies, 22, 409-425.

Li, S.-M., \& Yi, Z. (2007b). The road to homeownership under market transition Beijing, 1980-2001. Urban Affairs Review, 42, 342-368.

Mackie, P. K. (2012). Housing pathways of disabled young people: Evidence for policy and practice. Housing Studies, 27(6), 805821.

McKee, K. (2012). Young people, homeownership and future welfare. Housing Studies, 27(6), 853862.

Richard, R. (2018). 'Generation Rent' and intergenerational relations in the era of housing financialisation. Critical Housing Analysis, 5(2), 14-26.

Sato, H. (2006). Housing inequality and housing poverty in urban China in the late 1990s. China Economic Review, 17(1), 37-50.

State Council. (1998). Guowuyuan Guanyu Jingyibu Shenhua Chengzhen Zhufang Zhidu Gaige Jiakuai Zhufang Jianshe De Tongzhi (A Notification from the State Council on Further Deepening the Reform of Urban Housing System and Accelerating Housing Construction). Beijing.

Wang, Y., Li, Y., Huang, Y., Yi, C., \& Ren, J. (2020). Housing wealth inequality in China: An urban-rural comparison. Cities, 96, 102428.

Wang, Y. P., \& Murie, A. (2000). Social and spatial implications of housing reform in China. International Journal of Urban and Regional Research, 24(2), 397-417.

Wu, L., \& Zhang, W. (2018). Rural migrants' homeownership in Chinese urban destinations: Do institutional arrangements still matter after Hukou reform? Cities, 79, 151-158.

Yi, C., \& Huang, Y. (2014). Housing consumption and housing inequality in Chinese cities during the first decade of the twenty-first century. Housing Studies, 29(2), 291-311.

Zhang, L. (2010). In search of paradise: Middle-class living in a Chinese metropolis. Ithaca: Cornell University Press.

Publisher's Note Springer Nature remains neutral with regard to jurisdictional claims in published maps and institutional affiliations. 